\title{
THE PILE OF BODIES IN GRAPHIC NARRATIVES: VARIATIONS ON AN IMAGE
}

\author{
André Cabral de Almeida Cardoso \\ Universidade Federal Fluminense \\ Niterói, RJ, BR.
}

\begin{abstract}
The aim of this paper is to investigate a recurring image in graphic novels published from the 1980s to the present day: that of a pile of bodies on which the protagonist or another character in the narrative is placed. Variations on this image point to important representations of the body and personal identity in our society. They also problematize our perceptions of ourselves, of the world around us, and of our own memories. By comparing some of them, I will explore the tensions and contradictions present in these representations, and examine the ways in which they can lead to an expression of utopian desires.
\end{abstract}

Keywords: Utopia; graphic novels; body; identity.

There is a recurring image in commercial superhero comics which has been repeated so often that it has almost become a meaningless cliché. Its very repetition, however, attests to the fascination it holds. Versions of it appear in movie posters and book covers. In its most undiluted form, it shows a hero attacked by an impossible number of opponents whom he methodically knocks down. The bodies of the defeated fall around the hero, forming a pile which he seems to climb. The composition is usually vertical: a pyramid of bodies pointing upwards toward the triumphant hero and then even higher, to a point near the top of the image, as if the apotheosis of the hero had no bounds.

In what follows, I will explore the role this image assumes in different narratives. Even though the pile of bodies may not have a specific meaning in itself, it does evoke affect and it does influence the context in which it is inserted. Moreover, it turns up in graphic narratives of widely different genres and thematic concerns. Kristeva's notion of the abject, as well as
Mary Douglas' discussion on purity and pollution, will play an important role in my analysis, for the image of the pile of bodies consistently calls into question the establishment of boundaries and the safe isolation of the self. The materiality of the corpses and of the body of the character in contact with them will also play a central role in my analysis. Finally, I will try to point to a more positive aspect of this image, which, despite evoking the presence of death, nevertheless opens the possibility for the articulation of utopian desires.

\section{From the heroic to the abject}

I will begin my discussion with an example picked more or less at random from the vast visual repertoire of superhero comics. It presents the image of the pile of bodies in its typical heroic mode: 


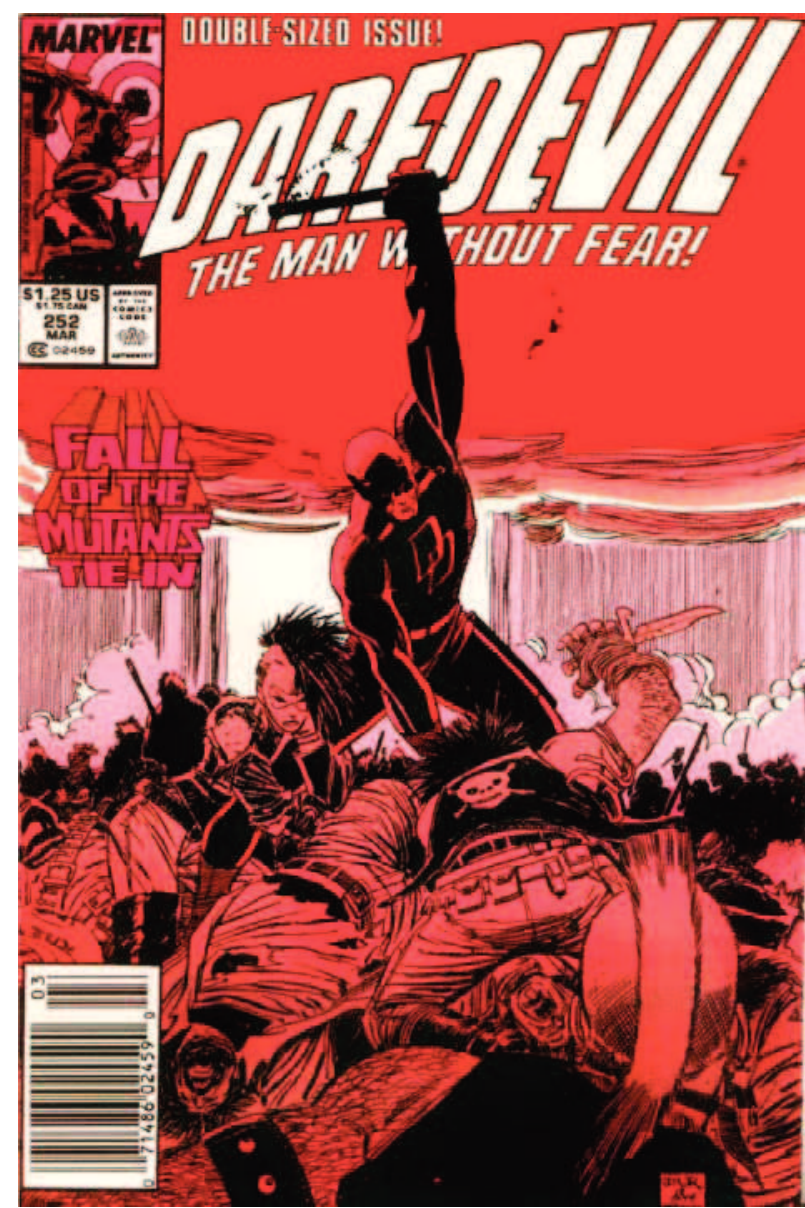

Fig. 1: Daredevil: The Man without Fear!, n. 252 (cover). Art by John Romita Jr. and Al Williamson

Several elements from the cover of Daredevil n. 252-the raised clubs and knives, the shadowy figures suggesting a barbarian horde, the frantic dynamism of the battling figures, and especially the young woman incongruously clinging to the hero's right leg-reveal its origins in the pulps. In fact, this cover looks like a blend of two paintings by Frank Frazetta inspired by the pulp hero Conan the Barbarian, created by Robert E. Howard:

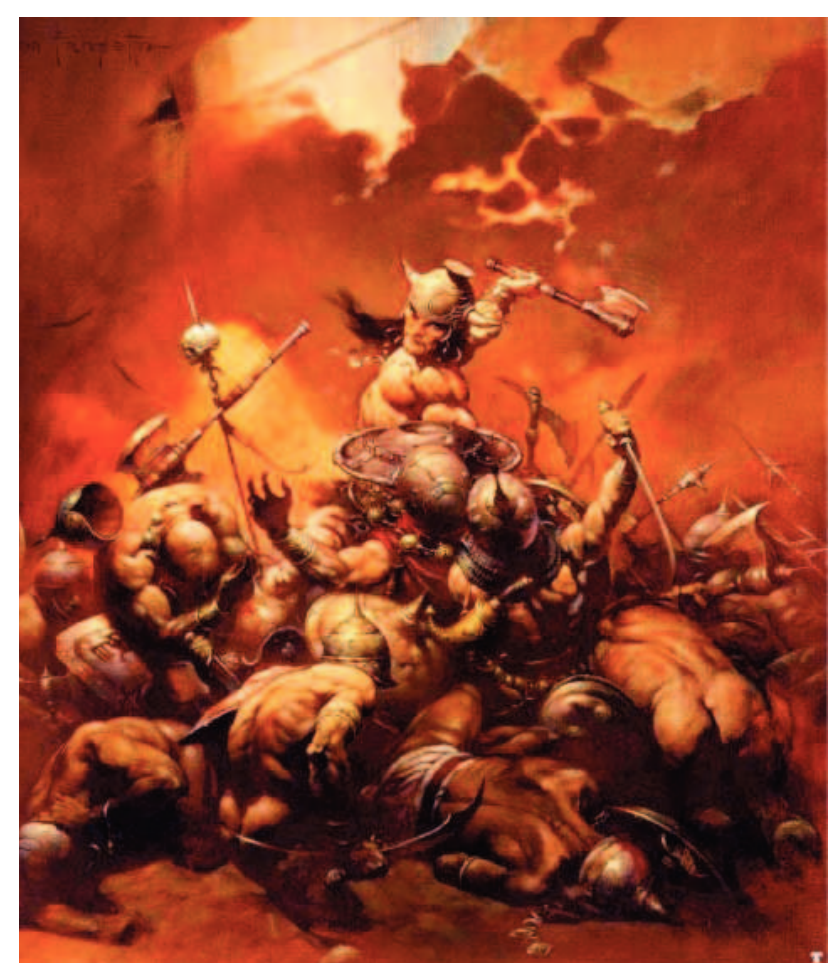

Fig. 2: Frank Frazetta, Conan the Destroyer.

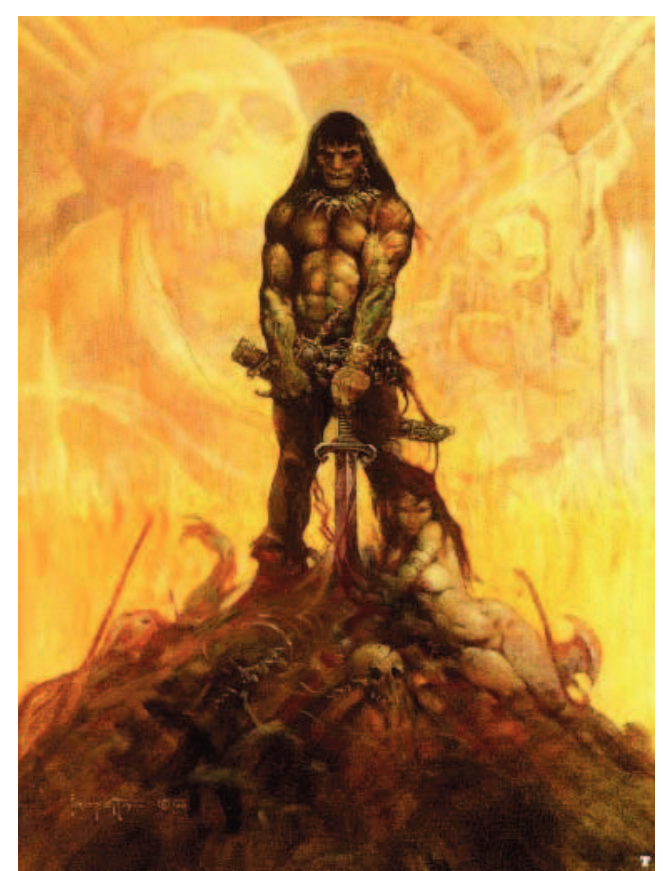

Fig. 3: Frank Frazetta, Conan the Adventurer.

Frank Frazetta, who began his career as an illustrator in the mid-1940s, would have a huge influence on fantasy art, especially on the sword-andsorcery subgenre, mainly because of his paintings featuring Conan the Barbarian. Most of these paintings offer a wish-fulfillment fantasy in which the viewer can identify with the power and vitality of the hero, 
whose feats are hyperbolically presented in one single image. The writhing horde surrounding the hero in Frazetta's Conan the Destroyer is a mass of powerful bodies subdued by the superior force of their opponent. Conan stands erect against his enemies, as they fall before him. The erotic energies involved in this tumultuous confrontation are more explicit in Conan the Adventurer, which seems to depict the aftermath of a similar battle. Now Conan rests above those he has vanquished, while his only obvious reward-the virtually naked woman who clings to his leg as if asking for protection-leans against him. On the cover of Daredevil n. 252, the two moments are fused together: the hero fights a seemingly endless horde of thugs at the same time that his potentially erotic reward already clings to him. Although the cover of Daredevil n. 252 can be read as a parodic appropriation of Frazetta's style, the message remains virtually the same: physical power equals sexual potency, and the subjugation (or destruction) of the enemy corresponds to the subjection of the object of desire.

These images celebrate the hero's prowess in battle: they are a sort of pop aristeia in visual form. The vertical triumphalism of their composition suggests vitality and sexual energy. On the other hand, a disquieting fascination with death creeps into these pictures. One cannot help but notice that the unstoppable energies displayed by Daredevil and Conan turn powerful bodies into lifeless corpses-on the cover of Daredevil n. 252, death is dealt out in industrial scale. Wherever they appear, variations of these images are characterized by excess: they depict an endless production of dead bodies, an unbounded reproduction of death. In Conan the Adventurer, sexual desire and the troubling presence of death are inextricably intertwined: at Conan's feet there is not only an alluring woman, but also a mass of decaying corpses. Death seems to be imbued with an erotic energy here.

In most manifestations of the image of the pile of bodies, its composing elements seem to be carefully organized so as to create precisely this effect. In a cover for The Uncanny X-Men, for instance, three heroes are attacked by a group of armed outlaws. Once more, the visual elements in the scene are displayed in the form of a pyramid culminating in the figure of the heroes, highlighted by a circular frame behind them. Our gaze is pulled towards their godlike appearance. They literally burst with energy, and their posture is confident and aggressive. One of them yields bolts of lightning in her hands, another is a knight in shining armor, his immaculate metal skin glistening in the light. The overall effect is not only one of power, but also of unsullied purity. And yet, these heroes are standing on what looks like ribcages and vertebrae:

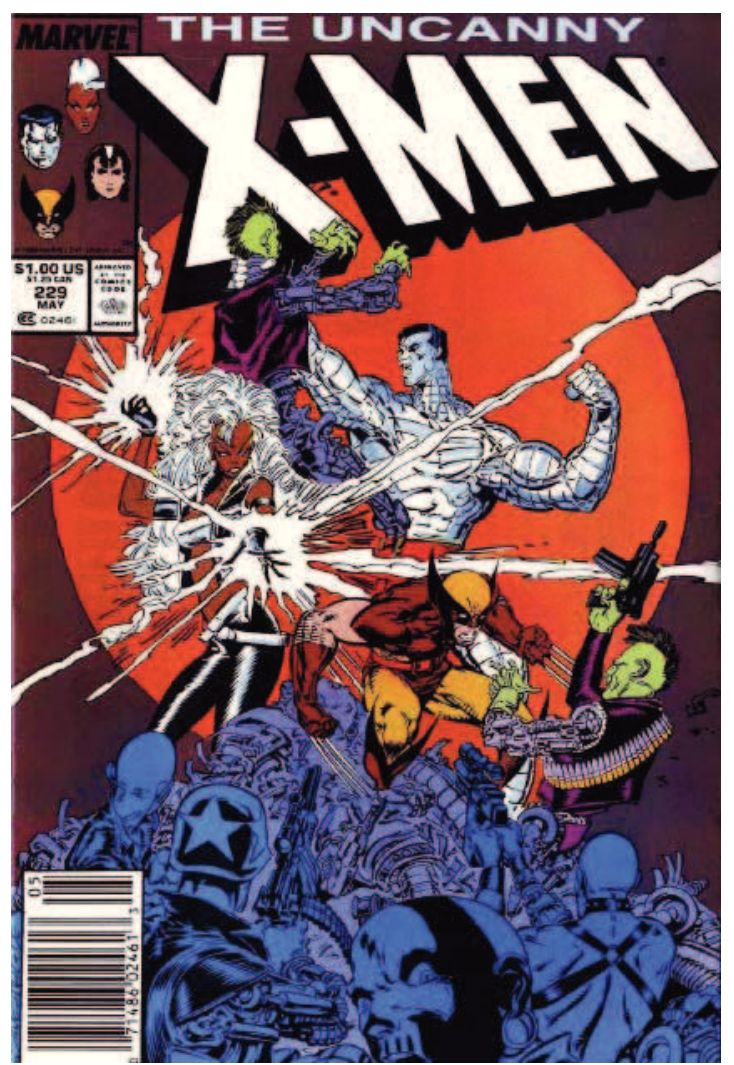

Fig. 4: The Uncanny X-Men, v. 1, n. 229 (cover). Art by Marc Silvestri and Dan Green.

However, what these heroes are doing is just as important as their appearance. They are destroying their attackers, and they are creating the very pile of bodies on which they stand. The more or less well-defined figures on the bottom of the page are turned into the indistinct mass of body-parts that functions as a pedestal for the heroes. They become corpses that ceaselessly reproduce themselves in a mindless process, losing all traces of personal identity. The X-Men's foes on this cover are actually cyborgs, with machine-like limbs. Their interior structure, however, looks far less mechanic. 
There seems to be a deliberate attempt to make the bodies of the defeated attackers look organic, creating the illusion that the heroes are standing on a pile of skeletons. This formal choice reinforces the presence of death in the picture, at the same time that libidinal desires are activated by the figure of the heroes (once again a sexually alluring woman is present; the men are muscular and confidently display their power). The pile of bodies brings together elements which usually stand in opposition to each other: the organic and the mechanic, vitality and death, attraction and repulsion.

We seem to be in the presence of what Julia Kristeva calls the abject: that which repulses and yet fascinates us, for it is the opposite of the self, the undefinable thing that must be rejected so that the ego may come into being. For Kristeva, the corpse is one of the most vivid manifestations of the abject. It does not symbolically represent death, it is an expression of the presence of death. It generates a kind of affect and not a representation, for it does not have a meaning: it simply is. Kristeva describes the experience of seeing a corpse as a sort of falling down, a breaking down of the world in which all borders are erased. The corpse "is death infecting life" (Kristeva 3-4).

At the same time that the pile of bodies on the cover of The Uncanny X-Men n. 229 brings up the possibility of this kind of infection, other formal devices are employed to block it and reinforce the purity of the heroes. The X-Men are drawn in full color, while their enemies (except for a couple of cyborgs in close contact with them) are uniformly blue. The remains of the defeated foes are also more or less colorless and indefinite, as if to offer a contrast with the heroes and render their deathly presence less concrete. The bearing of the heroes is also ambivalent. They seem morally unconcerned with the carnage they are carrying out, while the ethos of this particular graphic series and of the superhero genre as a whole calls for a more concerned attitude. In fiercely holding their position, they seem to be protecting the bodies of their enemies, as if they were guarding something precious.

Such ambiguities seem to be a central aspect of the image of the pile of bodies. They resurface, for instance, on the cover of an issue of Time MGMT, a much more recent graphic narrative. The basic visual elements remain the same as on the cover of The Uncanny X-Men n. 229 , but a series of inversions also occurs:

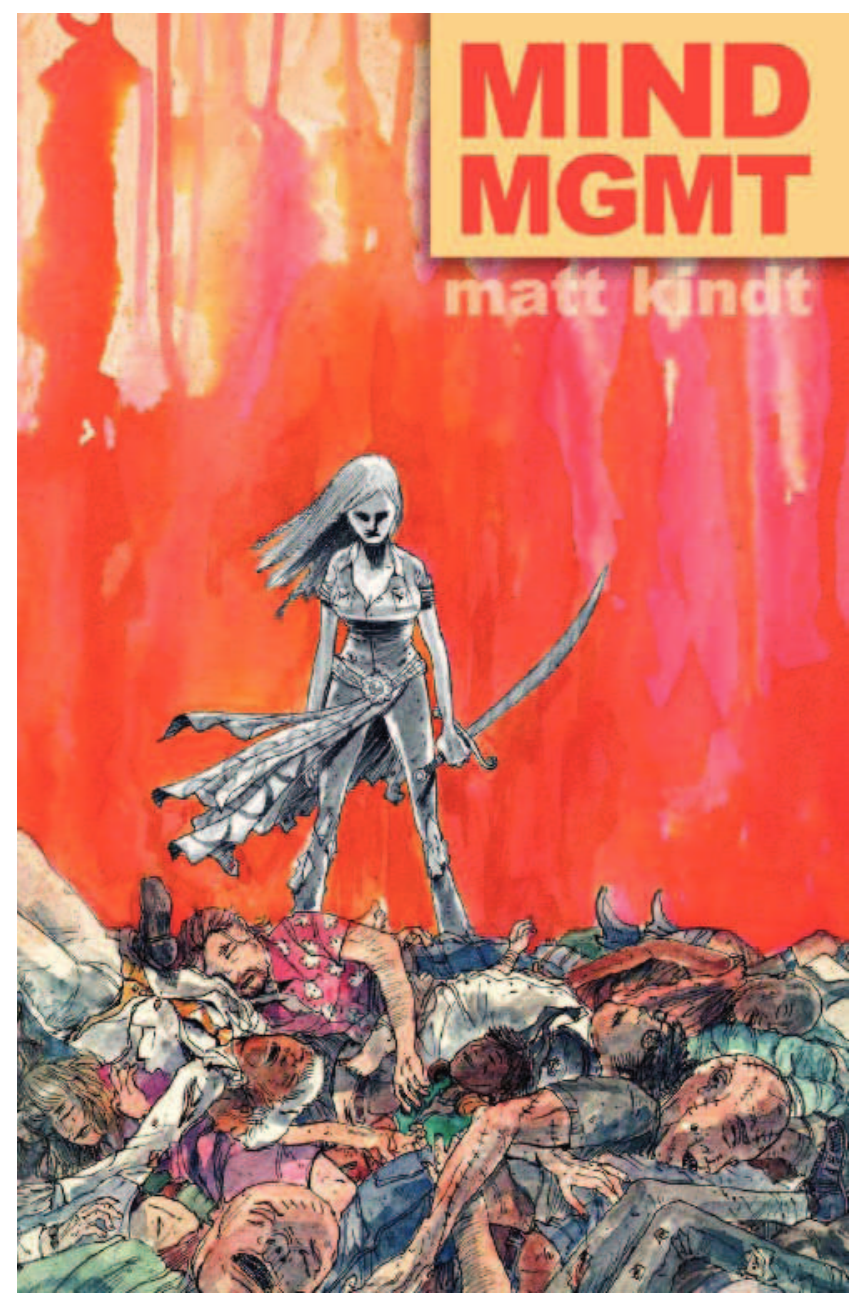

Fig. 5: Time MGMT, n. 28 (cover). Story and art by Matt Kindt.

Here, it is Meru, the protagonist of the narrative, who stands on the pile of bodies. She is depicted in shades of gray against a red backdrop suggesting blood. As opposed to the X-Men, she is the one who seems to fade away, while the bodies beneath her feet are brightly colored. As Conan and Daredevil, she holds a phallic weapon in her hand, but the action is already over, and the energy of the battle is replaced by a sense of melancholia. While the cover of The Uncanny X-Men n. 229 was clearly triumphalist, the cover of Time MGMT n. 28 is almost oppressive. Meru seems to be in mourning. The shadows on her downcast eyes imply she feels sad for the dead, although her upright posture and the sword pointing upwards are more suggestive of 
grim determination. The sword is also an indication of her responsibility in the killing.

An element of wish-fulfillment is still present in the image. In the beginning of the narrative, Meru was helpless and insecure, but now she stands above her defeated enemies, wearing the kind of exotic outfit in which she used to picture herself in her fantasies as a young girl, and which makes her look like a superheroine. None of the frantic enthusiasm on the covers of Daredevil and X-Men is present here, however. Meru looks less vivid than the corpses at her feet. The pile of bodies is no longer a pyramid that raises the hero ever higher in her apotheosis. It has been flattened. Actually, the position of the body on the extreme left suggests a downward movement, a depression at the top of the pile, as if Meru were sinking.

The ambivalence of the character's feelings is matched by the conflicting readings this image seems to entail. Does it still reaffirm the hero's power, or is it rather a representation of her moral defeat, the expression of her guilt for the carnage? Does it imply an intensification of the abject, insofar as Meru identifies with the dead, who seem to drag her down with them? Or is there a separation among them, marked by the way they are represented? As Kristeva's abject, the pile of bodies refuses a stable sense, at the same time that it demands our interpretation. Neither Meru nor the dead look at us, as if they were opaque objects who refuse to give us any clues to their purpose by not responding to our gaze. But their concrete presence silently questions us. The pile of bodies destabilizes meaning. It points to a crisis.

\section{The haunting}

"Narratives can make us understand. Photographs do something else: they haunt us", Susan Sontag declares in Regarding the Pain of Others (80). This statement also applies to the image of the pile of bodies in Maus, Art Spiegelman's classic graphic novel on the Holocaust. I do not mean to say that this image necessarily haunts those who see it, although no doubt it often does, but that it is an image about haunting:
Time flies...
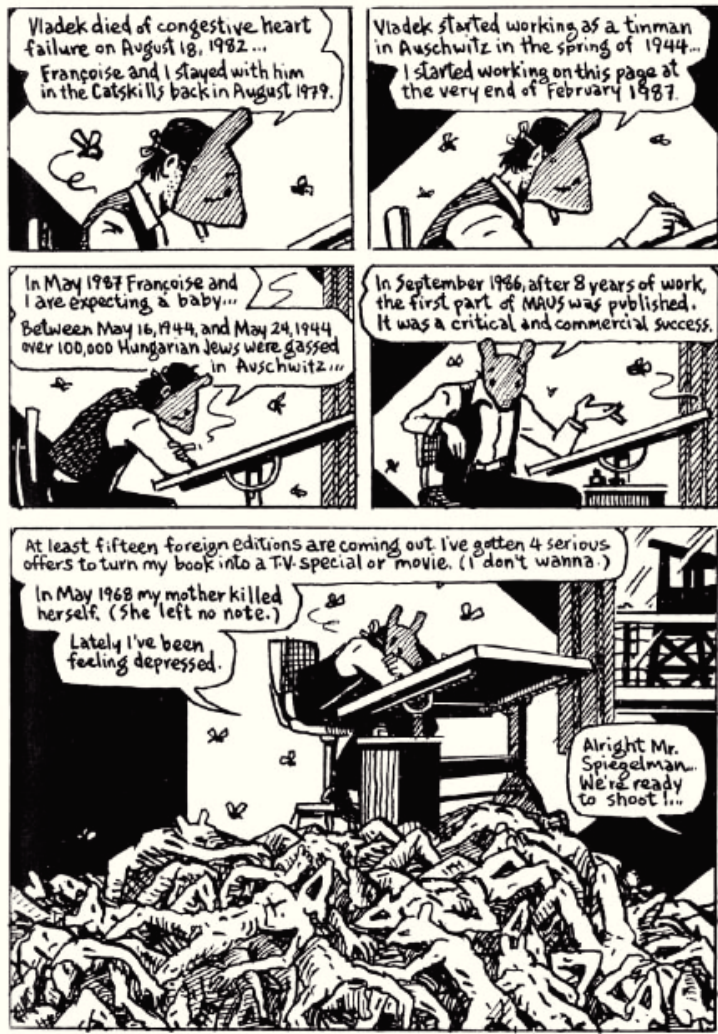

201

Fig. 6: Maus, vol. 2, p. 201. Story and art by Art Spiegelman.

In the beginning of his book on the uncanny, Nicholas Royle invokes the sensation of haunting, or being haunted, in order to introduce his subject, and goes on to argue that "the critical spectralization of feeling and belief" is one of the aspects of the uncanny $(1,24)$. For Royle, the uncanny presents "a pervasive linking of death, mourning and spectrality, especially in terms of storytelling, transgenerational inheritance and knowledge" (12).

The dead bodies under the cartoonist in Maus are a sort of spectral manifestation. They can be seen, they seem concrete, but they are actually part of his memories, or rather the image that haunts him after his father Vladek has told him the story of his life during the Holocaust. The whole composition of the scene is an attempt to visually represent how memory works and how it is constructed. For Freud, the uncanny is related to an affect that has been repressed but which later returns (O inquietante 360). This would explain a peculiar characteristic of the uncanny: the fact that it is not simply a manifestation of horror, of an unfamiliar 
danger, but rather an amalgamation of the strange and the familiar. In other words, the uncanny is the familiar rendered strange by the process of repression, and its nature is essentially ambiguous (Freud, $O$ inquietante 331-340). In the image of the pile of bodies from Maus, the uncanny manifests itself in the way the familiar, domestic environment of the cartoonist's studio is transformed by the unnatural intrusion of the harrowing image of the pile of corpses. The effect of a clash between the strange and the familiar is represented by a visual juxtaposition, and is reinforced by the fact that the cartoonist seems unaware of the bodies under him-an indication that they are to a large extent unconscious thoughts, or that they should have remained hidden, but have obscenely returned into view, which is another way Freud describes the mechanism behind the uncanny (O inquietante 338).

As Freud points out, one of the tropes that can generate the sensation of the uncanny is that of the double, which is connected to a stage in the development of the psyche in which there is no clear boundary between the self and the external world (O inquietante 354). Royle insists that the uncanny is connected to a loss of distinctions, to a perception of strangeness within the self, and a destabilization of time, space, order and sense (2). These views on the uncanny converge with Kristeva's notion of the abject. This erasure of boundaries and differentiation entailed by the uncanny and the abject is at the center of the construction of memory in Maus. In explaining why he has chosen the graphic novel as the medium to tell his story, Art Spiegelman claims that

What is most interesting about comics for me has to do with the abstraction and structurings that come with the comics page, the fact that moments in time are juxtaposed. In a story that is trying to make chronological and coherent the incomprehensible, the juxtaposing of past and present insists that past and present are always present-one doesn't displace the other the way it happens in film. (MetaMaus 165)

Juxtaposition appears here as a structuring technique inherent not only to comics as a form, but also to a specific representation of time that Spiegelman wants to achieve. Past and present cease to be separate moments in order to coexist simultaneously, in an indication of the permanence of the past in the present. The pile of bodies from the past uncannily reappears in the present, and is as tangible as the cartoonist himself and his drawing table. What is blurred in this juxtaposition is not only the boundary between the past and the present, but also the boundary between what is inside and outside the self: inner memory becomes a concrete, externalized presence.

This loss of personal identity goes hand in hand with the reduction of living bodies to lifeless corpses, their conversion into purely material objects, which, in its turn, threatens their possibility of conveying meaning. Sontag also calls our attention to the fact that the meaning of a photograph depends on how the picture is identified, on the words that insert it into a narrative $(25,80-81)$. The photograph of an atrocity runs the risk of simply generating shock, instead of leading to understanding; in time, as a photograph circulates and is reproduced, the specificity of the moment it has captured is forgotten, and it becomes a denunciation of human cruelty in general (Sontag 80, 109). The image of the pile of bodies works in a similar way, and it runs similar risks. As the war photographs Sontag discusses in Regarding the Pain of Others, this image shocks, but it may not lead to a real understanding of the Holocaust when detached from the narrative in which it is inserted: it may stop at the intense sensation it generates and remain simply a horrifying object.

As Spiegelman points out in MetaMaus, the endeavor to make sense of the past seems doomed to failure: the past is "incomprehensible", just as the abject is meaningless. The juxtaposition of past and present is not harmonious. It remains tense, just as the juxtaposition of the figure of the cartoonist and the pile of bodies creates its own tensions. It may indicate an integration of the cartoonist with the corpses and therefore with the past they represent. On the order hand, in order to survive, he must remain distinct, above the pile of bodies, thinking about them yet showing by his posture that he is not actually seeing or touching them. A complete identification with them would 
entail death, just as immersion in the abject means the dissolution of the self. In one sense, the cartoonist must reenact the rejection of the abject that Kristeva sees as the founding gesture of the self (3-4). On the other hand, some of the contagion must remain, so that Art may retain his identification with his father and turn Vladek's memories into his own-and, at the same time, turn the abject silence of the bodies into history.

This tension is graphically represented in the figure of Spiegelman himself. All characters in Maus are represented as animals: the Jews are mice, the Nazis are cats, the French are frogs, and so on. In the whole sequence involving the pile of bodies, however, the cartoonist is depicted as a man wearing the mask of a mouse. This representational strategy introduces a gap between Spiegelman as narrator and Spiegelman as a character in the story. It internalizes the fissures between the present and the past, and lived memory and narrated account. As Susan Sontag notes, "[t]he image as shock and the image as cliché are two aspects of the same presence" (20). As an image, the pile of bodies is part of Vladek's memories absorbed by Spiegelman; however, it also exists independently in Spiegelman's mind, as an image he creates after listening to Vladek's story. But this image is not autonomous: it echoes the photographs of the Holocaust which have proliferated since the end of World War II. Actually, these photographs seem more important to the visual structure of the pile of bodies than Vladek's personal recollections of the war, in which no such pile is mentioned. One reason for the cartoonist to feel frustrated is that, while trying to forge a personal connection with his father in which his own history might make sense, he can only imagine the past as a cliché of the Holocaust. The image of the pile of bodies, then, seems to belong to no one in particular. By the time Maus was published, it was already part of the widespread visual repertoire of the war. There is something established, official, about it-despite all its awfulness.

The image by itself, then, produces an intense affect, independent from the narrative in which it belongs. We seem to be faced here with one of the tensions Fredric Jameson discusses in his The Antinomies of Realism, between narrative drive and its suspension in favor of an intensification of affect. For Jameson, this tension lies at the center of the realist novel and is one of its structural elements. As Karl Erik Schøllhammer argues, this intensification of affect, this reinforcement of material sensation, is the dominant form realism has found to manifest itself in the last few decades, increasingly abandoning representation in order to focus on expression. This is the basic strategy adopted by Spiegelman in Maus, and I would like to suggest that it is actually the condition to create a sense of realism in this narrative. The use of striking images, their arrangement in separate panels, which breaks down the flow of time into distinctive moments, and their emotional impact, are essential for the sensation of density in the story, its materiality, and its existence as an account created by the convergence of different points of view: those of Spiegelman's father, of Spiegelman himself and of the reader, who is invited to react as a witness to the images presented to him.

I would like to conclude my discussion on the haunting effects of the pile of bodies with a few comments about one of the covers produced for the $100^{\text {th }}$ issue of The Walking Dead, a hugely popular graphic narrative which has been turned into a successful TV series. As in Maus, the image of the pile of bodies is used here to convey the sense that our relation to the past is always troubled and often riddled with guilt. 


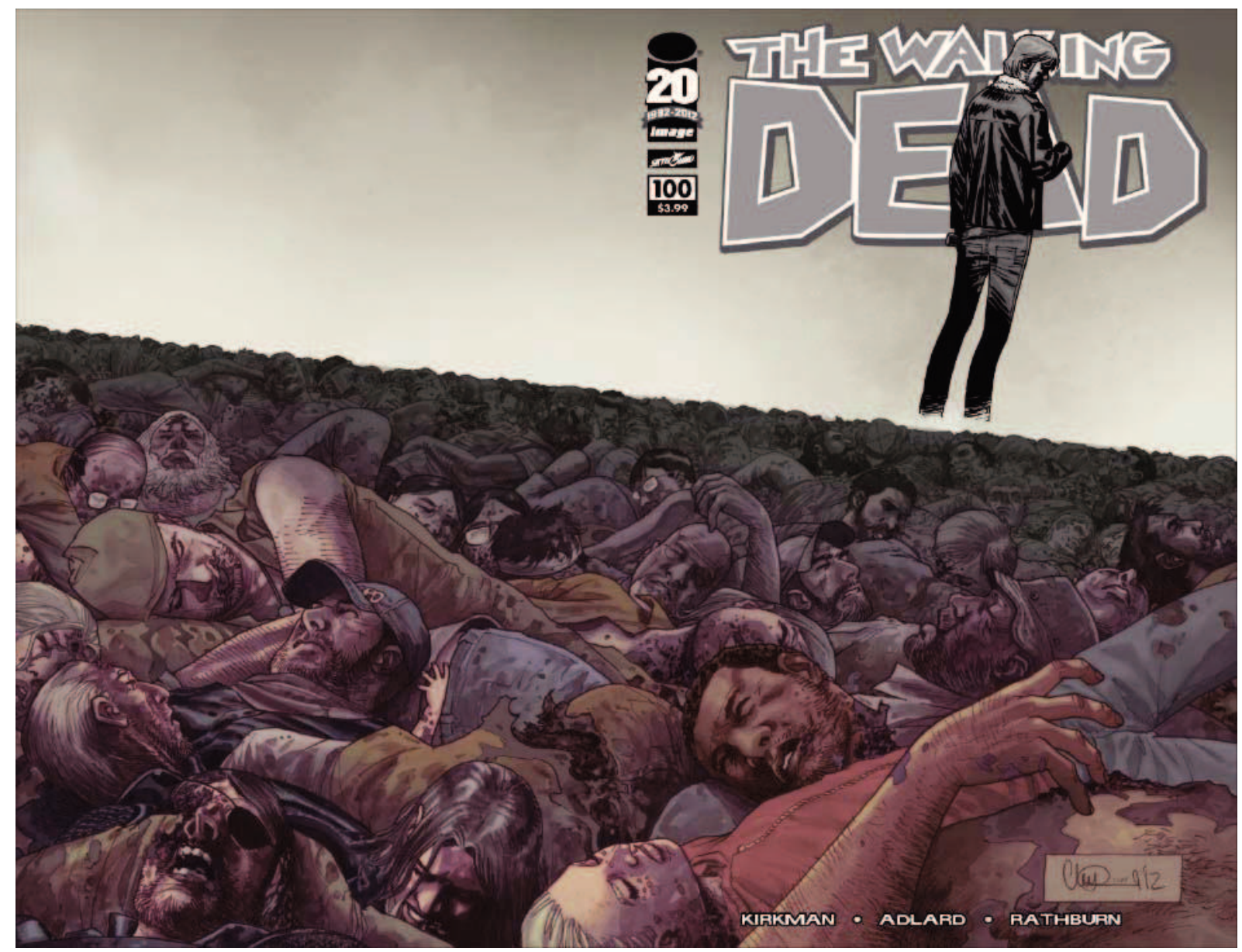

Fig. 7: The Walking Dead, n. 100 (cover). Art by Charlie Adlard and Cliff Rathburn

The composition of this illustration is very similar to the cover of Mind MGMT n. 28. Once again the protagonist is represented atop the pile of bodies in shades of grey and black, while the bodies themselves are in full-although subdued-color. The latter seem more distinct and therefore more concrete than the protagonist, who seems ghostly, his feet disappearing into mist without actually touching the bodies beneath him. As in other variations of the image of the pile of bodies, contagion is an important issue here. As in Mind MGMT n. 28, the protagonist merges with the dead, insofar as he is visually turned into a ghost. On the other hand, some distance is imposed between the corpses and the protagonist, since he does not seem to actually touch them. It is as if he is being protected from getting infected by the dead and instantly becoming one of them-a concern which makes sense in the universe of The Walking Dead, a narrative about the aftermath of a world-wide disease that transforms all the dead into zombies. In fact, as an emblem for memory, the image of the pile of bodies follows a logic of contagion: the past is accessed through contact with a mass of decaying corpses, whose presence invades the present. The fact that these corpses lose their distinctiveness the further back they are displayed is an indication that memory also decays, that it is constantly losing its distinctiveness as well.

The bodies on the foreground, on the other hand, are quite distinct. This creates a shock, for it is easy for the readers of The Walking Dead to recognize in them characters who have died in previous issues of the series. This is an important deviation from the way the pile of bodies is typically rendered, for usually it entails an erasure of personal traits. But this rupture with the tradition serves the specific purpose of intensifying affect. The image is supposed to move the reader, and to create a sense of empathy with the sorrow expressed by the figure of the protagonist. The intensification of affect is achieved here by the realistic depiction of these characters and of the wounds that resulted in their death, which is literally inscribed on their flesh. 
In The Walking Dead, the past becomes an increasing accumulation of dead bodies. Their apparent tangibility and their sheer number ensure that they will never go away. Although they are under his feet, they seem to weigh on the protagonist. As on the cover of Mind MGMT n. 28, the issue of responsibility is important here. Rick Grimes, the protagonist of The Walking Dead, constantly accuses himself of having failed the people he was supposed to protect. The ethos of power and potency of the hero is converted into mourning as the protagonist confronts the past, which reveals itself as an accumulation of losses. The contamination entailed by the pile of bodies reveals itself in all its poignancy: corpses from the past haunt the hero in the form of memories, but this causes the hero himself to become a ghost that haunts the past.

\section{Guilt, innocence, doubt}

There is always something hierarchical about the way the image of the pile of bodies is organized: on the cover of The Walking Dead n. 100, for instance, the bodies seem to crush the protagonist, but he is above them. This visual arrangement complicates the reading of the scene, and the moral positioning of the character in relation to the corpses seems to be at issue here. His body language indicates guilt for the procession of dead bodies that extends to the horizon. On the other hand, he seems distant, ready to fade in the distance, leaving the dead behind him.

I would like to argue that this moral ambiguity is a central issue in most variations of the image of the pile of bodies. An example from a graphic narrative published in the early 2010s may help clarify my point. Jeff Lemire's Sweet Tooth tells the story of Gus, a nine-year-old boy who grows in isolation in a postapocalyptic world devastated by a mysterious plague. The only ones immune to the disease are the children born after its outbreak, and all of them are hybrids of humans and animals. Gus himself is a hybrid, half boy and half deer. The origin of the epidemic is never fully explained, although apparently it is the revenge of ancient Eskimo gods for the defilement of their sacred place of rest by European missionaries. The narrative, then, becomes itself a hybrid, departing from science fiction and dovetailing into the fantastic. In any case, towards the end it becomes clear that Gus was the first hybrid born and that he probably was the trigger for the disease. This might be enough, then, to place him above his own pile of bodies:

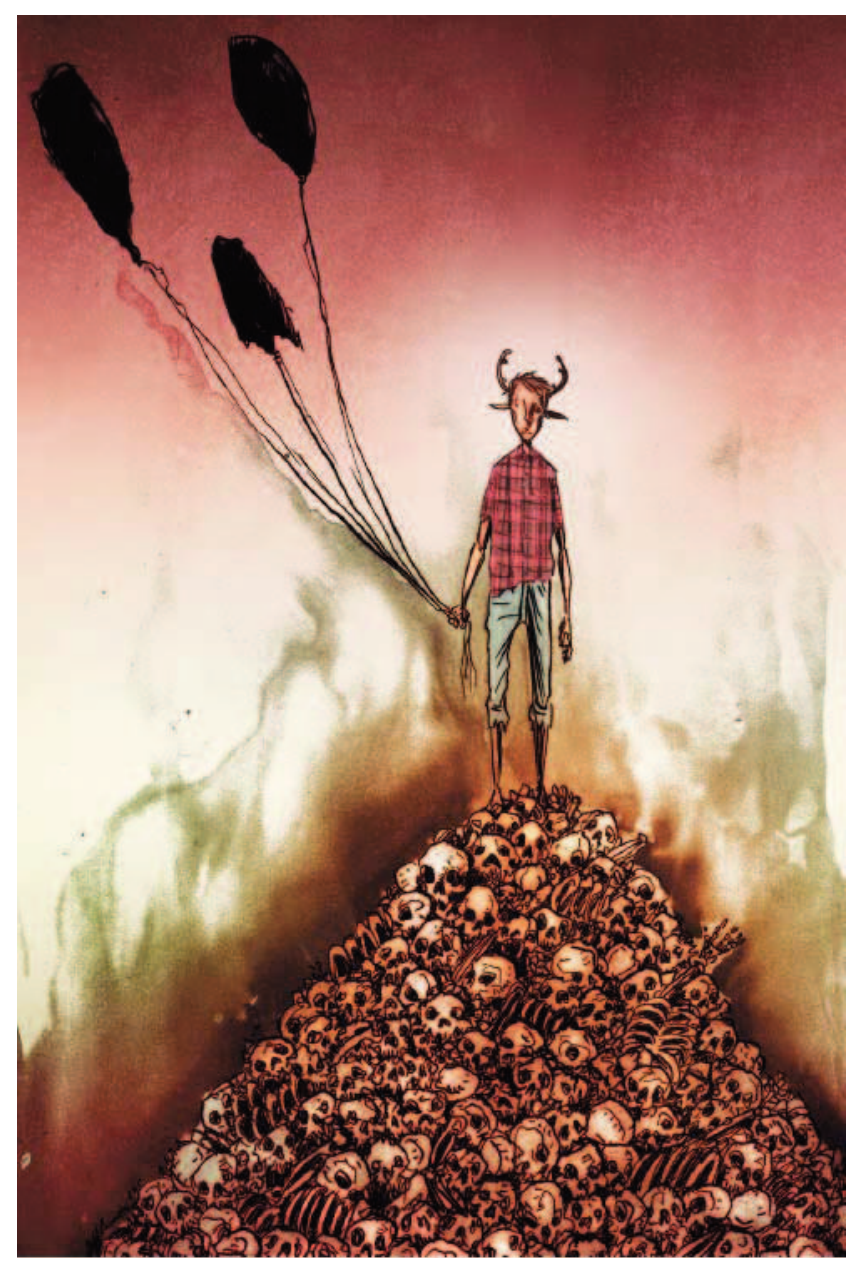

Fig. 8: Sweet Tooth, vol. 4, p. 134. Story and art by Jeff Lemire.

While in superhero comics the image of the pile of bodies bursts with energy, here it is static. Its composition itself suggests immobility, for neither Gus nor the pile of skeletons on which he stands seems capable of any movement. They are there simply to be seen and, once again, to shock the reader.

The erasure of individual traits from the bodies is more complete here than in the examples studied in the previous section, since nothing but bones and skulls are left. This also points to a vaster manifestation of death, one that goes further back in time, since the decomposition of the bodies is even more advanced than in Maus or The Walking Dead-actually, if 
decomposition were to advance any further, it would be impossible to recognize the remains as bodies at all. The abject, in terms of an effacement of boundaries, is even more present here. This is also true of the figure atop the pile of skeletons: this is an actual hybrid, human and animal at the same time.

Contagion is, of course, a central theme in Sweet Tooth, just as in The Walking Dead. It is visually represented here as the dark mist that rises from the bones and slowly envelops Gus, evoking pollution and the physical sensation of bad smell. Taking into consideration the plot of the narrative, it becomes clear that Gus stands on the corpses of those killed by the plague. The boy touches them with his bare feet, while the protagonist of The Walking Dead seemed to float above the bodies, without actually touching them. And unlike the heroes on the covers of The Uncanny X-Men and Mind MGMT, there is no color scheme to separate him from the dead. Everything in this image, then, reinforces the idea of contamination. Gus is immersed in impurity: there is little to distinguish the pile of bodies from a pile of refuse.

However, as Mary Douglas points out in Purity and Danger, cleanness and uncleanness are relative concepts, and what is pure in a certain context may be impure in another (10). Actually, Douglas' whole conceptualization of the notions of purity and impurity hinges on this tension. For Douglas, a culture considers impure or dirty anything that does not fit its systems of classification, anything that represents disorder (xvii, 2). As Douglas points out, hybridization is explicitly posited as an abomination in Leviticus, and it is at the core of the concept of the impure precisely because it mixes categories (6667). In what Douglas calls primitive culture, Gus himself would be considered impure, since he blends human characteristics with those of an animal. The notions of purity and impurity play a central role in the imaginary world of Sweet Tooth, and they seem to follow the same logic suggested by Douglas: as I have mentioned above, the disease that exterminates humankind in the narrative had its origins in an unintended-but nevertheless damning-encroachment on a clearly delimited sacred space. “Taboo is a spontaneous coding practice which sets up a vocabulary of spatial limits and physical and verbal signals to hedge around vulnerable relations. [...] Some of the dangers which follow on taboo-breaking spread harm indiscriminately on contact. Feared contagion extends the danger of a broken taboo to the whole community", Douglas argues (xiii). This is indeed what happens in Sweet Tooth: the boundaries protecting a sacred, tabooed space are ruptured, and the whole community pays the price by contagion-the community in question being the whole human race. Jeff Lemire apparently invokes the primitive (represented by an early twentieth-century Eskimo tribe under the pressure of colonization) as an imaginary domain in order to bring back its logic.

One would expect to find in Sweet Tooth, therefore, a clear distinction between what is pure and impure, a delimitation of areas that must be spared from pollution. What to make of the image of the pile of bodies in this case? If it highlights contagion, this would push Gus towards the territory of the impure and the condemnable, especially because Gus himself already represents a mixture of categories. But this would only be the case if the logic governing purity and pollution outlined by Douglas were in full effect in Sweet Tooth. At a certain level, it is indeed. As Douglas points out, pollution is not exactly an infraction of moral values, but an infraction of form (130): an individual may become unintentionally polluted if he or she happens to get in contact with anything the community considers impure. In Sweet Tooth, the first person to trespass on the sacred territory of the gods is an Englishman who had chosen to become a member of the Eskimo community and adopt their culture, but who unwittingly enters the cave where the gods slept. This is enough to trigger an outbreak of the disease that exterminates the Eskimo community, the missionaries who were trying to convert it to Christianity and the search party that had come over from Britain to find their missing compatriot. A century later, military scientists would find the bodies of the gods in the abandoned cave, and try to clone them so that they could be used as a weapon. This is the event that spreads the plague to the rest of the world. This revelation is made towards the end of the series, causing the narrative to veer back towards science fiction.

The generic instability of Sweet Tooth is connected to the way the notions of purity and impurity are articulated in the narrative. If at first pollution remains 
a matter concerning the formal arrangement of physical space, as in the societies discussed by Douglas, soon it becomes entangled with moral considerations. The logic of divine agency associated with tribal culture and with the marvelous elements of the story is juxtaposed to the logic of human action and responsibility associated with modern culture and with the science-fictional features of the narrative. Colonial exploitation, genocide (the British rescue expedition decimates the remnants of the Eskimo community), military authoritarianism, and the instrumentalization of people in a technocratic order all merge as fundamental sins of Western civilization that must be sacrificially expiated with the return of a mythical logic. Global condemnation, still based on the trespass of limits (the limits of human action in nature, for instance), becomes universal guilt.

The image of the pile of bodies gets tangled in the tensions created within this code of pollution. It, too, is structured on juxtaposition. In Sweet Tooth, however, the matter of moral responsibility seems more significant than in Maus or even The Walking Dead, where the innocence of the protagonists in relation to the pile of bodies is more or less established. For what exactly is Gus' relation with the bundle of skeletons on which he stands? Is he responsible for them, or is he another victim? Does his position on the top of the pile still indicate a hierarchical superiority? His ordinary, boyish clothes, his bland, almost sad or scared expression, and the balloons he holds in his hand are signs that stand for childish innocence. In fact, most elements in the narrative of Sweet Tooth emphasize Gus's innocence, from his naïveté in the beginning as he leaves his shelter in the woods, to the crystalline expressiveness of his deer-like eyes. Gus is often displayed as a victim of abuse, crying and asking for help. On the other hand, it is his birth that triggers the pandemic disease, and his representation at the top of the pile of bodies suggests his defilement. After all, the logic of contagion, as we have seen previously, is in full force in this image. The balloons Gus holds are themselves a mark of pollution: they are black, distorted and vaguely sinister, the toys of a perverted child. This is a fundamental ambiguity in the structure of the image itself: the figure in contact with the pile of bodies is, at the same time, in opposition to them and being absorbed by them.

This is a paradox that contaminates the narrative of Sweet Tooth as a whole. Innocence and purity are fundamental values in it, but it also values hybridity and liminality. Actually, the hybrid, as opposed to Douglas' proposition, becomes the ultimate representative of purity in Sweet Tooth, since it is consistently associated with childlike innocence, and it stands in stark opposition to the callousness and violence of the adult world. Nevertheless, Gus' ambiguous position at the top of the pile of bodies seems to imply something like a shared original sin, as if even the most innocent cannot help but be guilty with the rest of humanity. After all, even though the corpses are those of the victims of a disease, there is still something violent in the image. Why have these bodies not been buried? Who has been inconsiderate enough to simply sweep them aside as a pile of dirt, denying them their own personal identities?

\section{The gates of utopia}

The connection between the pile of bodies and violence is also a constant. It is particularly marked, however, when it is associated with a specific historical conflict, as in Maus. This is also the case of Thermidor, a stand-alone story originally published as issue 29 of The Sandman, a series written by Neil Gaiman in the late 1980s and early 1990s. The action of Thermidor takes place on the few days preceding the death of Robespierre in 1794, and it depicts in often grotesque detail the violence of the Reign of Terror during the French Revolution (at a certain point, there is a puppet show featuring the decapitated bodies of political prisoners killed at the guillotine). The narrative, however, is less concerned with the excesses committed during this specific historical period than with an indictment of human violence and abuse of power as a whole.

The plot of Thermidor involves the attempt by Johanna Constantine to retrieve the living head of Orpheus before it is destroyed by Robespierre and his allies, who are intent on eliminating all remnants of old myths from Republican France. Before running away from Paris, Johanna hides Orpheus among the recently severed heads awaiting burial in the lime-pits. Arrested 
by the revolutionaries, Johanna is forced to identify Orpheus among the other heads. She picks up his head and places it on top of the others. After that, she covers her ears and tells him to sing. Orpheus sings in Greek, but Johanna nevertheless manages to understand most of his words. "The head sang first of Blood, of the Baying Senseless Cries of the Mob, of the Anger of Women and Men; of the Worm that devours its own Flesh". Then Orpheus moves on to sing of "Freedom, of Liberty, of Love", and at this point he is joined by the voices of the other severed heads, who miraculously sing with him. Finally, his song denounces those who "are raised above the Crowd; who manipulate the Commonality"; in other words, he "sang of a dream-and of the ending of the Dream" (Gaiman et al. 21). Robespierre and his allies, who had not covered their ears and had been exposed to the full force of Orpheus' singing, fall into a sort of trance, and Johanna seizes this opportunity to escape.

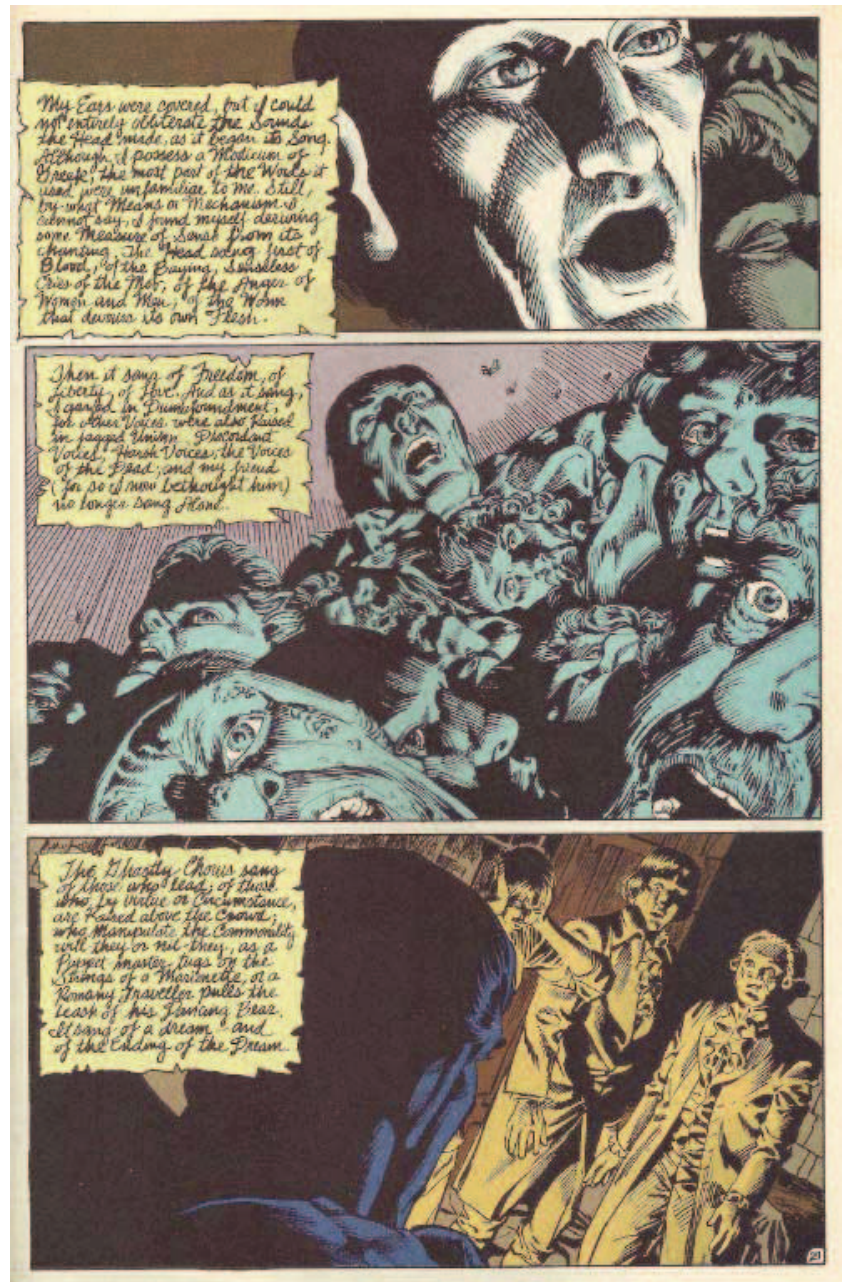

Fig. 9: Thermidor, p. 21. Story by Neil Gaiman, art by Stan Woch and Dick Giordano.
The image of the pile of bodies reappears, but now the corpses are mutilated, and only their heads are left. The inherent violence of this image is brutal and direct. The objective is to represent violence itself, violence against everybody. All the elements employed to establish the abject in other variations of the image of the pile of bodies (including the presence of flies to suggest decomposition) are present here. The contours of the pile itself remain vague, and it is impossible to determine how many heads are in it, since they seem to multiply themselves to infinity. As in Sweet Tooth, an advanced stage of deterioration suggests the passage of time, as if these singing heads have been abandoned for years, their voices reaching out from the past under the influence of the ancient head of Orpheus, himself a victim of irrational violence.

Indeed, what seems to make Orpheus a particularly apt speaker for the dead, one that allows their voices to blend with his own, is the fact that he had his body torn apart by a "bayed, senseless" mob of the kind he mentions in the beginning of his song. For there is something in this pile of heads in Thermidor that distinguishes it from the other piles of bodies I have discussed so far. Although there is still a character at the top, in this case he has the same substance as the rest, that is, Orpheus is a severed head among other severed heads, so much so that he could be hidden among them without being noticed. There seems to be more uniformity here, a stronger sense of identification. On the other hand, each head preserves its own features, and the voices of the dead are "discordant", but, even so, they sing "in jagged Union" (Gaiman et al. 21). What seems to be at stake here is not exactly the erasure of the self and its immersion in the indetermination of the abject, although something of this desire remains present, but rather the need to reach a consensus without suppressing the individual characteristics of each person (which would distinguish a harmonious multitude from the irrational and easily swayed mob). In other words, what is longed for in this scene from Thermidor is something like the universal consensus achieved through the free discussion of reasonable convictions, which Paul Ricœur proposes in the ninth section of 
his treatise on the self. This represents a commitment to the other which is an essential aspect of the good life according to Ricœur, and a fundamental element of its ethical dimension (275-347). This commitment is only possible through sympathy, solicitude towards the other and an exchange of feelings that does not entail an erasure of the self, for it is this movement of sympathy that allows us to see the other as unique and unreplaceable in our affections, which in its turn allows us to imagine ourselves as unique and unreplaceable to the other-a paradoxical search for equality through inequality (Ricœur 197-214). The pile of faces in Thermidor makes an appeal of this kind: while Orpheus gazes upward, towards some higher inspiration, the other heads in the central panel of page 21 stare at the reader, as if demanding sympathy or an ethical commitment.

Sympathy is an issue once again in a sequence of three pages in the third volume of Miracleman, a critical pastiche of superhero comics written by Alan Moore towards de end of the 1980s, with art by John Totleben. In the last page of this sequence, the eponymous hero of the story sits among the ruins of a section of London devastated in his final battle against his archrival. Miracleman holds a skull in a gesture that, as the photographs of the victims of the Holocaust, has become a cliché: like Hamlet, he ponders about life and death. He is surrounded by skeletons and other skulls, the remains of civilians who had died during the fight. The battle occurred two years before, but the ruins have been left untouched, as a memento mori. Like Meru, from Time MGMT, and Rick Grimes, from The Walking Dead, Miracleman has a mournful expression, and his face is covered by shadows.

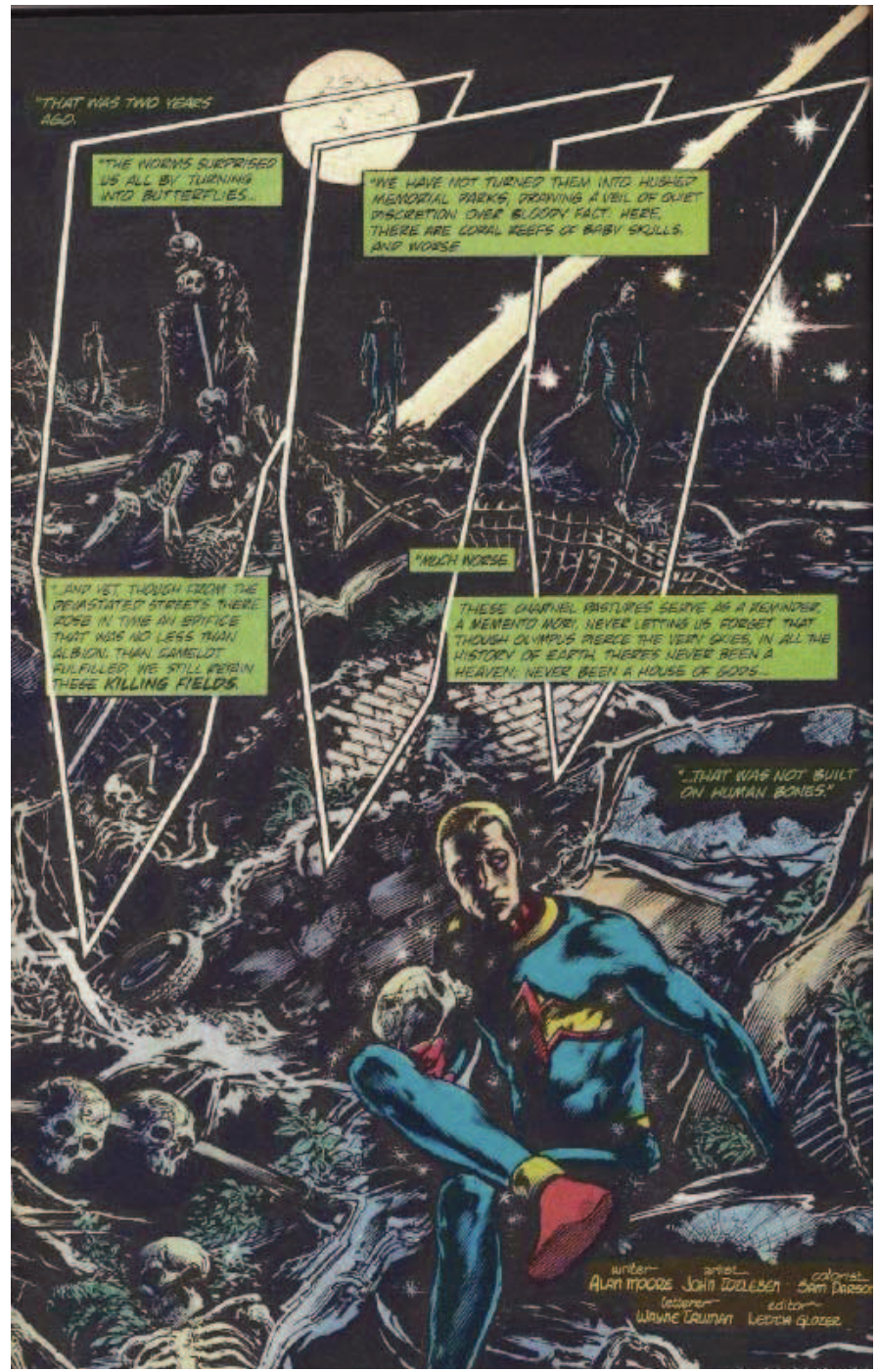

Fig. 10: Miracleman, v. 3, p. 92. Story by Alan Moore, art by John Totleben.

Miracleman is placed among the bones, and not on the top of a pile. He is among the dead, but unlike Orpheus, he is clearly not one of them. On the contrary, he scintillates with power, he is young and full of life, his body is muscular and elegant. And yet the visual composition of the frame does not reveal the same triumphant grandiosity the heroes display on the cover of The Uncanny X-Men n. 229. The skulls and ruins around Miracleman are manifestations of the other, and he pities them. But his posture reveals discomfort, and there is more than sympathy in his gaze, which he keeps averted from the reader, as if in shame: there is also guilt. Miracleman's thoughts on this page show the reason for his guilt. The whole place is not only a memorial for the dead, but also a reminder of the price paid to achieve utopia, a society in which everyone 
112 André Cabral de Almeida Cardoso, The Pile of Bodies in Graphic Narratives: Variations on an Image

could have the perfect body and the godlike powers of a superhero. There is no real logical connection between the defeat of the supervillain and the establishment of utopia in Miracleman, for, although London had to be rid of the sadistic destruction caused by the hero's antagonist, this does not entail that a new utopian order should necessarily be established; order could simply be restored, as is usually the case in superhero comics. All the death and destruction displayed on the previous pages of Miracleman are rather a rite of passage or a sacrifice. As Mary Douglas notes, "[d]anger lies in transitional states, simply because transition is neither one state nor the next, it is undefinable" (119). As in the other versions of the image of the pile of bodies I have discussed here, the juxtaposition of the hero and the dead in Miracleman creates the sense of an interstitial space. It stands for the undefinable state of transition between familiar reality and a utopian society which has already been announced, but which has not yet been described at this point of the narrative. For Douglas, there is "a power in the forms and other power in the inarticulate area, margins, confused lines, and beyond the external boundaries" (122). In Miracleman, this power manifests itself in the indescribable devastation unleashed in the fight between the hero and his enemy. The literal power of the two opponents is an equivalent for the awesome power of possibility in the moment of transition.

Before Miracleman is shown in deep reflection holding a skull, there is a double-spread illustration depicting the apocalyptic landscape of London immediately after the battle:

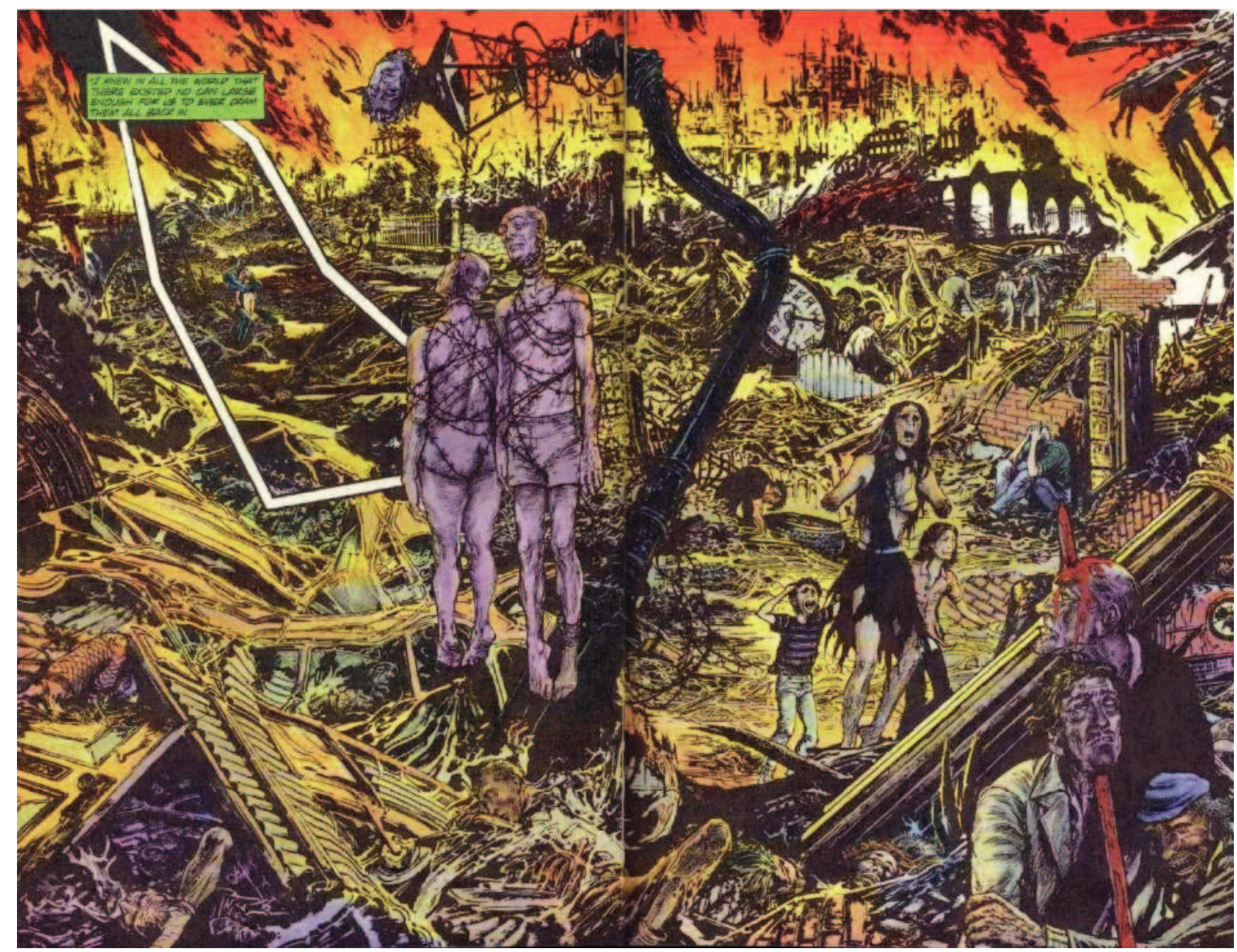

Fig. 11: Miracleman, v. 3, p. 90-91. Story by Alan Moore, art by John Totleben.

In this image, the hero is almost lost in the background, holding a dead body on his lap. The foreground is occupied by the bodies of people who 
have been tortured to death. A woman, her arms burned off and her eyes gauged out, totters among the wreckage with two crying children. Towards the bottom of the page, we can see impaled heads, dismembered limbs, bodies torn in half, bones showing under shredded skin. The abject reappears in all its horror. But although the graphic detail of these killings is repulsive, those mangled bodies also cause fascination. This is a picture of the violent disruption that marks the transition to utopia, the radical break which, for Jameson, is the task of utopia to imagine and to posit not only as a possibility, but also as a necessity (Archaeologies 231232). In the logic of Miracleman, these mangled bodies, this explosion of violence, are indeed necessary to bring in utopia. They are the final catharsis, the ultimate rite of passage that will substitute the self-devouring worm of Thermidor for the worms which, after being let out of their cans, turn into butterflies:

I thought about the firemen and the dumbstruck ambulance crews. The world in which they tried to sleep that night would be a different world to that in which they had begun their day. Different forever: all the cats were now out of the bag, the worms at last freed from their tin. I knew in all the world that there existed no can large enough for us to ever cram them all back in. That was two years ago. The worms surprised us all by turning into butterflies... (Moore and Totleben 89-92; emphasis in the original.)

I would like to suggest, however, that the mangled bodies in this harrowing double spread are necessary for another reason. As Mary Douglas argues,

[ $\mathrm{t}$ ] he body is a model which can stand for any bounded system. Its boundaries can represent any boundaries which are threatened or precarious. The body is a complex structure. The functions of its different parts and their relation afford a source of symbols for other complex structures. We cannot possibly interpret rituals concerning excreta, breast milk, saliva and the rest unless we are prepared to see in the body a symbol of society, and to see the powers and dangers credited to social structure reproduced in small on the human body. (142)
If the body is indeed a symbol for social structure, especially in a ritual (and there is much of ritual magic in the transition towards utopia in Miracleman), then a representation of utopia must necessarily involve a representation of the body. The mutilated bodies scattered on the devastated landscape of Miracleman, with their blood spilling out and their insides torn into view, are in themselves a representation of the rupture of boundaries that is a necessary step in the creation of a utopian society. If utopias, as Jameson states, are a by-product of Western modernity (Archaeologies 11), this happens because it is with the onset of modernity that society has learned to reflect upon itself as another, and to wonder about its own boundaries and its own structures. The abject bodies in Miracleman are a way to think of the limits of the human and of modern society, or at least a way to represent a fascination with this matter. The most basic function of utopia may not be to present an ideal society, but to question the boundaries of any society, to map where they may possibly lie, and to push them to their limits.

We may now have an explanation for the strange fascination the image of the pile of bodies holds from its origins in fantasy art to its fusion with photographs of the Holocaust. A disturbing blend of power, sexual desire, and morbidity is indeed at the core of its structure, and this is the necessary condition for its efficiency. The recompense for the hero's efforts and vitality has always been the fusion of the self to the boundless vastness represented by the erasure of boundaries in the pile of bodies, an immersion in the oceanic feeling that Freud describes in Civilization and Its Discontents as the state of ideal happiness which precedes the formation of the ego, and in which there is no distinction between the self and the rest of the world. This state goes back to the earliest infancy, and is the more positive equivalent of Kristeva's notion of the abject. It cannot coexist with the repression imposed by social rules and the disappointments offered by reality. It can remain, however, as a desire. It is this desire that lies deep within the pile of bodies. But in order to achieve it, society must first be destroyed, for the social body, as Mary Douglas points out, is structured around a set of carefully drawn distinctions. This generates guilt and 
explains the sense of mourning that often accompanies the image of the pile of bodies. But this image is always double, for at the top of the mass of bodies stands the individual. This visual organization expresses yet another desire: dissolving the self in the shapelessness of the abject while still keeping the integrity of the individual subject. In its many incarnations, the image of the pile of bodies speaks of the impossibility of this desire, the rage at its frustration, and the longing for its realization.

\section{References}

Claremont, Chris (story), Marc Silvestri (pencils) and Dan Green (inks). The Uncanny X-Men, v. 1, n. 229. New York: Marvel Comics, 1988. Cover image available at: $<$ http://marvel.wikia.com/wiki/Uncanny_X-Men_ Vol_1_229>. Accessed on: 21 Sept. 2015.

Douglas, Mary. Purity and Danger: An Analysis of Concept of Pollution and Taboo. 1966. Routledge Classics Edition. London and New York: Routledge, 2002.

Frazetta, Frank. Conan the Adventurer. The Art History Archive - Fantasy Art. Available at: <http://www. arthistoryarchive.com/arthistory/fantasy/images/ FrankFrazetta-Conan-the-Adventurer-1966.jpg>. Accessed on: 21 Sept. 2015.

Conan the Destroyer. The Art History Archive - Fantasy Art. Available at: < http://www. arthistoryarchive.com/arthistory/fantasy/images/ FrankFrazetta-Conan-the-Destroyer-1971.jpg>. Accessed on: 21 Sept. 2015.

Freud, Sigmund. Civilization and Its Discontents. 1961. New York and London: W. W. Norton, n/d.

"O inquietante". Obras completas vol. 14: História de uma neurose infantil ["O homem dos lobos"], Além do princípio do prazer e outros textos [1917-1920]. São Paulo: Companhia das Letras, 2010. 328-376.

Gaiman, Neil (story), Stan Woch (pencils) and Dick Giordano (inks). Thermidor. The Sandman 29. New York: DC Comics, 1991.

Jameson, Fredric. Archaeologies of the Future: The Desire Called Utopia and Other Science Fictions. 2005. London and New York: Verso, 2007.

The Antinomies of Realism. Kindle ed. London and New York: Verso, 2013.

Kindt, Matt (story and art). Mind MGMT 28. Milwaukie: Dark Horse Comics, 2014. Cover image available at: $<$ https://www.darkhorse.com/Comics/25-709/MINDMGMT-28>. Accessed on 22 Sept. 2015.
Kirkman, Robert (story), Charlie Adlard (art) and Cliff Rathburn (gray tones). The Walking Dead 100. Berkeley: Image Comics, 2012.

Kristeva, Julia. Powers of Horror: An Essay on Abjection. 1980. New York: Columbia UP, 1982.

Lemire, Jeff (story and art). Sweet Tooth. 6 vols. New York: DC Comics, 2010-2013.

Moore, Alan (story) and John Totleben (art). Miracleman, v. 3. Forestville, CA: Eclipse, 1990.

Nocenti, Ann (story); John Romita Jr. and Al Williamson (art). Daredevil: The Man without Fear! 252. New York: Marvel Comics, 1988. Cover image available at: $<\mathrm{http}: / /$ marvel.wikia.com/wiki/Daredevil_Vol_1_252>. Accessed on: 21 Sept. 2015.

Ricœur, Paul. O si-mesmo como outro. São Paulo: Martins Fontes, 2014.

Royle, Nicholas. The Uncanny. Manchester: Manchester UP, 2003.

Schøllhammer, Karl Erik. "Realismo afetivo: evocar realismo além da representação". Estudos de Literatura Brasileira Contemporânea 39 (2012): 129-148.

Sontag, Susan. Regarding the Pain of Others. 2003. Kindle ed. London: Penguin, 2004.

Spiegelman, Art (story and art). Maus: A Survivor's Tale. New York: Pantheon Books, 1991.

MetaMaus. New York: Pantheon Books, 2011.

Recebido em: 02/06/2015 Aceito em: 14/09/2015 